\title{
Milk Products and Postmodern Humans: Public Education Fundamentals
}

\author{
A. Nikkhah \\ Department of Animal Sciences, Faculty of Agricultural Sciences, University of Zanjan, Zanjan, Iran. \\ Email: nikkhah@znu.ac.ir
}

Received December 22 ${ }^{\text {nd }}, 2010$; Revised January $16^{\text {th }}, 2011$; Accepted March $6^{\text {th }}, 2011$.

\begin{abstract}
Milk production in ruminants necessitates renovation of least available plant materials into most enriched nutrients. This involves pregastric microbial rumen fermentation of plant cells and production of volatile fatty acids (VFA) as substrates for mammary milk lactose, fat and protein synthesis. Thus, milk contains numerous bioactive substances functioning beyond solely their nutritive value. Essential amino acids, specialized casein, lactalbumins and globulins, peptides, nucleosides, nucleotides, unsaturated fatty acids such as conjugated linoleic acids, sphingomyelins, fat soluble vitamins and minerals of mainly calcium are principal examples. Whey proteins are insulinotropic, medium chain fatty acids improve insulin sensitivity, and calcium favorably influences fat distribution. Peptides and calcium can reduce blood pressure and cholesterol. Dairy consumption benefits folate availability and lowers blood homocystein and heart attack risks. Very early ( $<3$ mo of age) neonatal cow milk intake has been related to insulin-dependent diabetes. Nonbreast milk intake during early stages of life is unarguably uncommon. Modern nutrition does in no standard circumstances authorize feeding such quite young neonates non-breast milks. Milk sufficiency for neonatal brain, nervous and immune systems, and bone development and tissue growth for even up to $2 \mathrm{yr}$ without major needs for alternative foods is an evolutionary verification for its irreplaceable role in human nutrition. However, the increasing concerns of cardiovascular disorders, hypertension, and related complexities in modern populations due to improper nutrition have contributed to forming a fallacious public perception about milk in general and milk fat in particular as a possible risk factor. Despite such a functional nature of milk in improving human health, the confusion exists where education is suboptimal. Insightful education on milk science must accompany research to enable the public to discern a pseudoscience that unconsciously disregards milk as an animal fat food with serious health risks. With limited saturated fat intake from non-milk sources, increased milk consumption could bear a multitude of positive impacts on health even with high fat content. Milk is a collection of bioactive substances with unique nutritional properties that synergistically optimize the health of mind and physics in different age groups.
\end{abstract}

Keywords: Science, Milk, Health, Education, Functional Food, Volatile Fatty Acids (VFA)

\section{Introduction}

Milk production in ruminants is a bio-complex process that necessitates conversion and renovation of least available plant materials, such as cellulose, into most invaluable nutrients namely lactose, amino and fatty acids, and energizing water soluble vitamins [1]. These developments involve pregastric rumen fermentation of plant cells to produce volatile fatty acids (VFA) and microbial proteins, supplying most of the substrates for milk secretion $[1,2]$. As a result, milk contains many bioactive substances that function beyond their sole nutritive value [3]. Hence, milk is considered the most natural functional food (Figure 1). Essential amino acids, specialized proteins such as casein and peptides, lactalbumins and immunoglobulins, nucleosides, nucleotides, unsaturated fatty acids of mainly conjugated linoleic acids, sphingomyelins, fat soluble vitamins and calcium are vital examples $[3,4]$. Crucially, milk sufficiency for neonatal developments of brain network, nervous and immune systems, and skeletal frame all occur during the first few months of life without demands for alternatives foods. This provides an evolutionary attestation for the irreplaceable milk role in creating next generations [1]. The objective is to review novel milk nutritional properties and highlight public education commitments for 


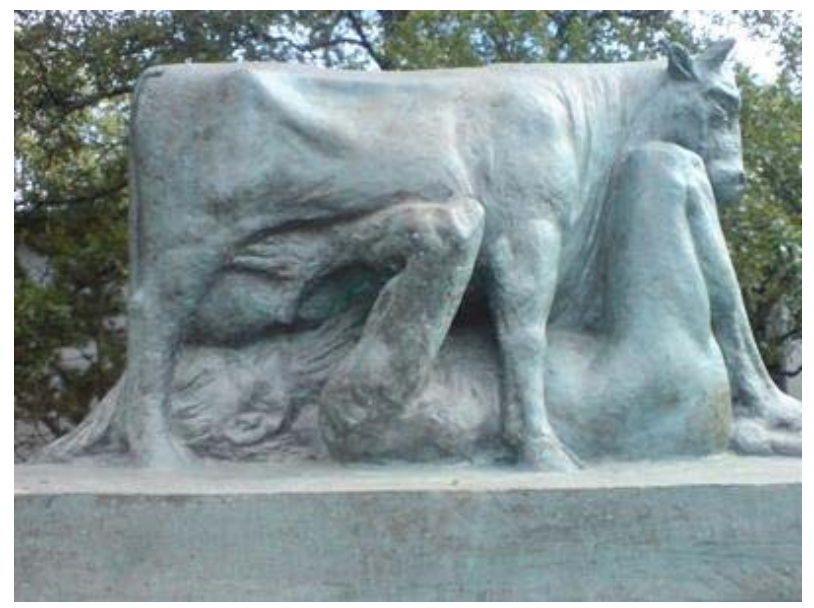

Figure 1. Ruminant milk and human health describes historical relations of man and the nature.

more efficient future human health benefits from milk and dairy products in general.

\section{Intuitions and Discussion}

The increasing modern era's concerns from cardiovascular, cognitive and aging complexities due to improper nutrition of non-milk ingredients appear to have alarmingly contributed to forming a fallacious public acuity about milk as a risk factor to optimum health [5]. For instance, very early ( $<3$ mo after birth) neonatal cow milk intake has been related to insulin-dependent diabetes [6,7]. Apart form bioreasons for such a relationship, non-breast milk consumption during very early stages of life is unarguably uncommon. Modern nutrition does in no standard circumstances authorize feeding such quite young neonates non-breast milks.

Population studies with compelling scientific application to real life scenarios demonstrated that unlike unsubstantiated beliefs, cow milk is not responsible for the major gastrointestinal related immune malfunctions [8]. Moreover, consuming cow milk by lactating mothers has proved to enrich breast milk beta-lactoglobulin and ovalbumin components [9]. Furthermore, youngsters consuming cow milk develop more standard body frame structure, whereas children deprived of milk intake exhibit poor bone health $[10,11]$. In complementary addition, what make ruminant milk exclusive are its processing and manipulation opportunities to better meet human nutrient requirements with no major health compromises. Enrichment with vitamin $\mathrm{E}$ and skim milk production from immunized cows for lowering blood cholesterol in hypercholesterolemic patients are amongst key examples $[12,13]$.

Most recently, conjugated linoleic acid (CLA) isomers of about 20 , notably CLA cis 9 trans $11(75 \%-90 \%)$ and
CLA trans10 cis12 from cow and goats milk have been emerging as novel agents with anti-carcinogenic, antiatherogenic, anti-inflammatory, and anti-lipogenic effects [14-16]. These effects protect against hypertension, cardiovascular disease (CVD) and progressive obesity. Accordingly, considerable research has focused on altering modern dairy cows and somewhat goats nutrition programs to improve milk nutrient profile, and enhance components with human health implications [15]. These are besides milk immunoglobulins beneficial impacts against Enterotoxigenic Escherichia coli [17]. Another group of milk bioactives include casomorphins, immunostimulating peptides, and ACE-inhibitory peptides. These substances form prime structures of milk proteins and act as plausible physiological modulators during milk digestion along the gut. Thus, such modulators can provide essential sources for designing commercial bioactive features or "functional foods" [18].

Recent observational studies report no increased CVD with increased milk or other dairy products intake [19, 20]. Dairy consumption has in several cases reduced the incidence of one or more metabolic syndromes [20]. Whey proteins are insulinotropic, medium chain fatty acids improve insulin sensitivity, and alongside calcium may favorably influence body weight and fat distribution. Peptides and calcium can reduce blood pressure and blood cholesterol. Additionally, dairy consumption benefits folate availability and thereby lowers circulating homocystein levels and heart attack risks [20].

Notwithstanding such recent emphases on the functional nature of milk in improving human health status in different populations, major confusions exist where education is suboptimal. Insightful education must commit to distinguishing science from pseudo-science of ruminant milk implications for the 21'st century's stressful times. Such science embodied with research evidence will enable the public to discern the pseudo-science that has likely unconsciously or deliberately disregarded milk and introduced it only as an overly saturated animal fat food with risks to human health. It is reasoned that animal fat in the form of milk should not be considered biologically similar to non-milk animal fats, simply because milk fats are accompanied by numerous various substances, each with distinctive benefits [3,18-20]. Even, evidence exists that medium- and short-chain fatty acids of milk specifically butyric acid, publically considered possibly unhealthy, improve intestinal fat and nitrogen assimilation and insulin sensitivity [21,22].

\section{Conclusions and Implications}

Milk is considered the most natural functional food. The increasing concerns from cardiovascular, cognitive and aging complexities in modern populations, mostly due to 
improper nutrition and lifestyle have wrongly contributed to forming a fallacious public perception about milk as a risk factor to optimal health. With limited saturated fat intake from non-milk sources, increased lower fat milk intake should lead to a multitude of health benefits. Substantive emphasis on public education of science and pseudo-science of milk intake is inevitable. Proper education is the gold missing piece of an accurate civic perception of milk intake relationship with the fitness of mind and physics in different human age groups.

\section{Acknowledgments}

The Ministry of Science, Research and Technology and University of Zanjan (Zanjan, Iran) are thankfully acknowledged for supporting the author's programs of improving science education worldwide.

\section{REFERENCES}

[1] A. Nikkhah, "Ruminant Milk and Human Wellbeing: A Multi-Species Review," Nova Science Publishers Inc., New York, 2010.

[2] H. H. Gordon, S. Z. Levine, H. and A. McNamara, "A Comparison of Human and Cow's Milk," American Journal of Diseases of Children, Vol. 73, 1947, pp. 442452.

[3] A. Donnet-Hughes, N. Duc and P. Serrant, "Bioactive Molecules in Milk and Their Role in Health and Disease: The Role of Transforming Growth Factor- $\beta$," Immunology and Cell Biology, Vol. 78, 2000, pp. 74-79.

[4] K. Stelwagen, E. Carpenter, N. Haigh and A. Hodgkinson, "Immune Components of Bovine Colostrum and Milk," Journal of Animal Science, Vol. 87, No. 13 (Supplement), 2009, pp. 3-9. doi:10.2527/jas.2008-1377

[5] A. J. Lanou, "Should Dairy Be Recommended as Part of a Healthy Vegetarian Diet? Counterpoint," American Journal of Clinical Nutrition, Vol. 89, No. 5, 2009, pp. 1638S-1642S. doi:10.3945/ajen.2009.26736P

[6] H. C. Gerstein, “Cow's Milk Exposure and Type I Diabetes Mellitus: A Critical Overview of the Clinical Literature," Diabetes Care, Vol. 17, No. 1, 1994, pp. 13-19. doi:10.2337/diacare.17.1.13

[7] F. W. Scott, "Cow Milk and Insulin-Dependent Diabetes Mellitus: Is There a Relationship?" American Journal of Clinical Nutrition, Vol. 51, No. 3, 2005, pp. 489-491.

[8] M. Knip, Q. Vaarala and J. Kokkonen, "Cow Milk is Not Responsible for Most Gastrointestinal Immune-Like Syndromes-Evidence from a Population-Based Study," American Journal of Clinical Nutrition, Vol. 82, No. 6, 2005, pp. 1327-1335.

[9] Y. Fukushima, Y. Kawata, T. Onda and M. Kitagawa, "Consumption of Cow Milk and Egg by Lactating Women and the Presence of Beta-Lactoglobulin and Ovalbumin in Breast Milk," American Journal of Clinical Nu- trition, Vol. 65, No. 1, 1997, pp. 30-35.

[10] T. Okada, "Effect of Cow Milk Consumption on Longitudinal Height Gain in Children," American Journal of Clinical Nutrition, Vol. 80, No. 4, 2004, pp. 1088-1089.

[11] R. E. Black, S. M. Williams, I. E. Jones and A. Goulding, "Children Who Avoid Drinking Cow Milk Have Low Dietary Calcium Intakes and Poor Bone Health," American Journal of Clinical Nutrition, Vol. 76, No. 3, 2002, pp. 675-680.

[12] A. Golay, "Cholesterol-Lowering Effect of Skim Milk from Immunized Cows in Hypercholesterolemic Patients," American Journal of Clinical Nutrition, Vol. 52, No. 6, 1990, pp. 1014-1019.

[13] K. C. Hayes, A. Pronczuk and D. Perlman, "Vitamin E in Fortified Cow Milk Uniquely Enriches Human Plasma Lipoproteins," American Journal of Clinical Nutrition, Vol. 74, No. 2, 2001, pp. 211-218.

[14] M. A. McGuire and M. K. McGuire, "Conjugated Linoleic Acid (CLA): A Ruminant Fatty Acid with Beneficial Effects on Human Health," Journal of Animal Science, Vol. 77, No. E-Supplement, 2000, pp. 1-8.

[15] A. L. Lock and D. E. Bauman, "Modifying Milk Fat Composition of Dairy Cows to Enhance Fatty Acids Beneficial to Human Health," Lipids, Vol. 39, No. 12, 2004, pp. 1197-1206. doi:10.1007/s11745-004-1348-6

[16] G. N. W. Haenlein, "Goat Milk in Human Nutrition," Small Ruminant Research, Vol. 51, No. 2, 2004, pp. 155163. doi:10.1016/j.smallrumres.2003.08.010

[17] C. O. Tacket, G. Losonsky, H. Link, Y. Hoang, P. Guesry, H. Hilpert and M. M. Levine, "Protection by Milk Immunoglobulin Concentrate against Oral Challenge with Enterotoxigenic Escherichia Coli," New England Journal of Medicine, Vol. 318, No. 19, 1988, pp. 1240-1243. doi:10.1056/NEJM198805123181904

[18] R-J. Xu, "Bioactive Peptides in Milk and Their Biological and Health Implications," Food Reviews International, Vol. 14, No. 1, 1998, pp. 1-16. doi: $10.1080 / 87559129809541147$

[19] M. Pfeuffer and J. Schrezenmeir, "Bioactive Substances in Milk with Properties Decreasing Risk of Cardiovascular Diseases," British Journal of Nutrition, Vol. 84, 2000, No. 1 (Supplement), pp. S155-S159.

[20] M. Pfeuffer and J. Schrezenmeir, "Milk and the Metabolic Syndrome," Obesity Reviews, Vol. 8, No. 2, 2007, pp. 109-118. doi:10.1111/j.1467-789X.2006.00265.X

[21] Z. Gao, J. Yin, J. Zhang, R. E. Ward, R. J. Martin, M. Lefevre, W. T. Cefalu and J. Ye, "Butyrate Improves Insulin Sensitivity and Increases Energy Expenditure in Mice," Diabetes, Vol. 58, No. 7, 2009, p. 1509. doi:10.2337/db08-1637

[22] P. Tantibhedhyangkul and S. A. Hashim, "Medium-chain Triglyceride Feeding in Premature Infants: Effects on Fat and Nitrogen Absorption," Pediatrics, Vol. 55, No. 5, 1975, pp. 359-370. 